\title{
Spontaneous Activity Signatures of Morphologically Identified Interneurons in the Vestibulocerebellum
}

\author{
Tom J. H. Ruigrok, ${ }^{1}$ Robert A. Hensbroek, ${ }^{2}$ and John I. Simpson ${ }^{2}$ \\ ${ }^{1}$ Department of Neuroscience, Erasmus Medical Center Rotterdam, 3000 CA Rotterdam, The Netherlands, and ${ }^{2}$ Department of Physiology and \\ Neuroscience, New York University School of Medicine, New York, New York 10016
}

Cerebellar cortical interneurons such as Golgi cells, basket cells, stellate cells, unipolar brush cells, and granule cells play an essential role in the operations of the cerebellum. However, detailed functional studies of the activity of these cells in both anesthetized and behaving animals have been hampered by problems in recognizing their physiological signatures. We have extracellularly recorded the spontaneous activity of vestibulocerebellar interneurons in ketamine/xylazine-anesthetized rats and subsequently labeled them with Neurobiotin using the juxtacellular technique. After recovery and morphological identification of these cells, they were related to statistical measures of their spontaneous activity. Golgi cells display a somewhat irregular firing pattern with relatively low average frequencies. Unipolar brush cells are characterized by more regular firing at higher rates. Basket and stellate cells are alike in their firing characteristics, which mainly stand out by their irregularity; some of them are set apart by their very slow average rate. The spontaneous activity of interneurons examined in the ketamine/xylazine rabbit fit within this general pattern. In the rabbit, granule cells were identified by the spontaneous occurrence of extremely high-frequency bursts of action potentials, which were also recognized in the rat. On the basis of these observations, we devised an algorithm that reliably determined the identity of $75 \%$ of the cells with only $2 \%$ incorrect classifications. The remaining cells were placed into border categories within which no classification was attempted. We propose that this algorithm can be used to help classify vestibulocerebellar interneurons recorded in awake, behaving animals.

\section{Introduction}

The Purkinje cells of the cerebellum are among the most investigated neurons in the brain. To a large extent, this is attributable to their unique discharge of two distinct types of action potentials, which enables their positive identification when making in vivo recordings (Granit and Phillips, 1956). However, to understand cerebellar cortical processing it is necessary to take into account the interplay with the cerebellar cortical interneurons. In addition to granule cells, at least five types of morphologically distinct interneurons have been described in the cerebellar cortex [i.e., Golgi, basket, stellate, Lugaro, and unipolar brush (UB) cells]. To understand the functional role of all these neuronal types, a physiological identification that could be linked to a morphological characterization would be paramount (Simpson et al., 2005). Indeed, Holtzman et al. (2006) have used recording of spontaneous activity and subsequent anatomical identification to differentiate Golgi cells from Purkinje cells using the median interspike interval, the modal interspike interval, or the mean instantaneous frequency. That study was aided by the fact that recordings were done near the surface of the cerebellum so recording depth could be used to determine whether the recordings were in the granular

Received April 9, 2010; revised 0ct. 25, 2010; accepted 0ct. 27, 2010.

This work was supported by the Dutch Ministry of Health, Welfare, and Sports (T.J.H.R.) and National Institutes of Health Grant NS-13742 (J.I.S.). We thank E. Sabel-Goedknegt and J. van der Burg for their expert technical assistance.

Correspondence should be addressed to Tom J. H. Ruigrok, Department of Neuroscience, Erasmus Medical Center Rotterdam, P.0. Box 2040, 3000 CA Rotterdam, The Netherlands. E-mail: t.ruigrok@erasmusmc.nl.

DOI:10.1523/JNEUROSCI.1959-10.2011

Copyright $\odot 2011$ the authors $\quad 0270-6474 / 11 / 310712-13 \$ 15.00 / 0$ or the molecular layer. When recordings are done at deeper levels with more complex foliations, such as in the case of the nodulus or the flocculus, the location of a recording from a particular layer is harder to determine and thus layering becomes less useful in identifying which cerebellar cell type is encountered. One, therefore, needs another method that is able to distinguish among multiple cell types.

We set out to record the spontaneous activity of interneurons in the vestibulocerebellum of anesthetized rats and then to label them using the juxtacellular technique described by Pinault (1996). We show that different classes of interneurons can be identified on the basis of statistical measures that characterize their spontaneous firing patterns. We constructed a decision algorithm that reliably indicates whether a spontaneous activity pattern is derived from either a Golgi cell, a UB cell, a basket or stellate cell, or a granule cell. In the anesthetized rabbit, the same general characteristics of the four cell types were also found. The decision algorithm based on spontaneous activity in anesthetized animals can also be applied to distinguishing among interneurons in awake, behaving animals before recording responses to vestibular and visual stimulation (Simpson et al., 2005; Hensbroek et al., 2006, 2007). A preliminary report of part this study has been published in short form (Simpson et al., 2005).

\section{Materials and Methods}

We used 23 male Wistar and 4 male Long-Evans rats. Approval for these experiments, which were conducted in Rotterdam, was obtained from a national committee overseeing animal experiments and all procedures adhered to the European guidelines for the care and use of laboratory animals (Council Directive 86/6009/EEC). Rabbit data were obtained 
from acute experiments in five Dutch belted rabbits, performed in New York. These experiments conformed to the Principles of Laboratory Animal Care and were approved by the Institutional Animal Care and Use Committee of New York University School of Medicine.

Surgery, neuronal recording, and juxtacellular labeling. Rats were anesthetized with an intraperitoneally administered mixture of ketamine $(100 \mathrm{mg} / \mathrm{kg})$ and xylazine $(3 \mathrm{mg} / \mathrm{kg})$. Surgical levels of anesthesia were monitored by the absence of pinch withdrawal reflexes and of rhythmic whisker movements. When necessary, supplementary doses were administered to maintain surgical levels of anesthesia. Body temperature was monitored and kept within physiological limits using a servo-controlled heating pad. After anesthesia was induced, the animals were placed in a stereotactic head holder, and the posterior cerebellum was accessed as described previously (Ruigrok et al., 1995; Voogd et al., 2003). In brief, after midline incision of the skin and the dorsal neck musculature, the neck muscles were spread and held by a clamp. Most of the vertical part of the occipital bone was then removed. After the dura mater was incised and reflected, the posterior cerebellar lobules became available for neuronal recording. To enhance recording stability, the exposed parts of the lower brainstem and cerebellum were covered with $2 \%$ agar in saline.

Filament-containing glass micropipettes with a tip of $\sim 1 \mu \mathrm{m}$ were filled with a $2-3 \%$ solution of Neurobiotin (Vector Laboratories) in $0.5 \mathrm{M}$ $\mathrm{NaCl}$ (impedance, $8-20 \mathrm{M} \Omega$ ). Lobules IX and $\mathrm{X}$ were accessed by horizontal penetrations and the places of entry and recording depths were logged. Typically, individual tracks were at least $750 \mu \mathrm{m}$ apart. In some animals, the flocculus was approached in the near horizontal plane at an angle of $\sim 50^{\circ}$ from the midline (Ruigrok et al., 1992). Electrical activity was monitored by an initial $10 \times$ amplification using an intracellular recording amplifier (IR 283; Neuro Data Instruments) followed by a $100 \times$ extracellular amplifier (Cyberamp 380; Molecular Devices), and the recordings were digitized at $22 \mathrm{kHz}$ and stored on videotape (NeuroCorder; DR 484; Neuro Data). Off-line analysis was performed with Spike2 (CED) and Microsoft Excel software. Spontaneously active cells that did not have the complex spike activity characteristic of Purkinje cells, but displayed positive/negative going biphasic spikes of at least 0.5 $\mathrm{mV}$, were recorded usually for at least $1 \mathrm{~min}$. After that time, juxtacellular delivery of Neurobiotin was attempted by passing gradually increasing positive current pulses (up to $10 \mathrm{nA}, 200 \mathrm{~ms}$ on, $200 \mathrm{~ms}$ off) through the pipette using the current delivery capability of the intracellular recording amplifier (Simpson et al., 2005). These pulses were usually superimposed on a small negative continuous current of $0.5 \mathrm{nA}$. Modulation of the firing frequency of a unit usually occurred suddenly as the current was slowly increased. As quickly as possible after this entrainment occurred, the current was reduced so that the neuron was not overdriven. Pulses ranging from 1 to $5 \mathrm{nA}$ were usually able to maintain a stable entrainment for a period of at least $3 \mathrm{~min}$ and up to $10 \mathrm{~min}$. During the entrainment period, Neurobiotin transfer to the recorded cell takes place and the neuron is juxtacellularly labeled (Pinault, 1996).

Rabbits were anesthetized with an intramuscular injection of a mixture of ketamine $(45 \mathrm{mg} / \mathrm{kg})$ and xylazine $(5 \mathrm{mg} / \mathrm{kg})$ and mounted in a stereotactic frame with the nose bone at $57^{\circ}$ to the horizontal. The animal was placed on a heating pad to maintain a physiological body temperature. Anesthetic levels were monitored by the absence of palpebral reflexes and pinch withdrawal, and supplemental doses were given as required. The dorsolateral cerebellum was exposed and the flocculus was accessed with a microelectrode at $37-27^{\circ}$ to the vertical axis (De Zeeuw et al., 1995). Individual tracks were spaced at least $750 \mu \mathrm{m}$ apart. Recording and juxtacellular labeling procedures were similar to those described above for the rat experiments.

Histology. Thirty to $90 \mathrm{~min}$ after the last juxtacellular staining attempt and up to $6 \mathrm{~h}$ after the first staining attempt, the animals were deeply anesthetized by an intraperitoneal (rat) or intravenous (rabbit) overdose of pentobarbital. They were subsequently perfused through the heart by an initial flush of buffered saline that was followed by $4 \%$ paraformaldehyde in $0.05 \mathrm{~m}$ phosphate buffer containing $4 \%$ sucrose. The brain was extracted and the cerebellum and brainstem were blocked, postfixed for $2 \mathrm{~h}$, and stored in phosphate buffer containing 10\% sucrose. After embedding in 10\% gelatin (Pijpers et al., 2005; Ruigrok and Apps, 2007), blocks were stored in $30 \%$ sucrose in phosphate buffer until sectioning.
Transverse sections were cut at $80 \mu \mathrm{m}$ and sequentially stored in numbered vials. After rinsing in phosphate buffer containing $0.4 \%$ Triton $\mathrm{X}-100$ (three times $10 \mathrm{~min}$ ), sections were incubated overnight according to the $\mathrm{ABC}$ Elite protocol (Vector Laboratories). Next, they were thoroughly rinsed and incubated with $\mathrm{DAB}(0.025 \%), \mathrm{H}_{2} \mathrm{O}_{2}(0.005 \%)$ with added cobalt and nickel ions $\left(\mathrm{CoSO}_{4}, 0.01 \%\right.$; $\left.\mathrm{NiSO}_{4}, 0.01 \%\right)$ for $15-20$ $\mathrm{min}$. Sections were again rinsed in phosphate buffer and mounted sequentially from a gelatinized chromic alum solution (Ruigrok and Apps, 2007), and the slides were air dried and counterstained with thioinin.

Sections were systematically examined with a Leica DMR microscope equipped with a digital camera (Leica DC-300). Points of entry and the course of pipette tracks were carefully documented. The distance between sections generally served as a measure for the depth of located cells. In this way, recovering stained neurons and relating them to the physiologically recorded data set was possible in most instances. All recovered neurons were photographed at various magnifications. Selected photos were assembled in CorelDraw 11.0, after some correction for brightness and contrast in Corel Photopaint 11.0.

Classification of spontaneous activity patterns. Statistical measures of spontaneous activity were calculated from a train of interspike intervals recorded usually for $60 \mathrm{~s}$; for a few cells $(n=9)$, the calculations were based on a recording of at least $30 \mathrm{~s}$ (average, $46 \mathrm{~s}$ ). The mean, median, $\mathrm{SD}$, coefficient of variation (SD divided by the mean), and dispersion (SD squared divided by the mean) were calculated for the distribution of the following measures: the interspike intervals (ISIs), the difference between successive ISIs, the natural logarithm of the ISIs (in milliseconds), the instantaneous frequency, the difference between successive instantaneous frequencies, and the natural logarithm of instantaneous frequencies. The kurtosis and skewness of both the ISIs and of the difference between successive ISIs were also calculated. In addition, the CV2, the $\mathrm{MAD}$, the ISI variation, and the variation in frequency were determined. CV2 is defined as the mean of two times the absolute difference of successive ISIs divided by the sum of both intervals (Holt et al., 1996). MAD is defined as the median absolute deviation from the median ISI (Vos et al., 1999). ISI variation is defined as the mean of the successive ISI differences divided by the mean ISI, and frequency variation is similar to that but uses instantaneous frequency. Finally, the ISIs and the difference in successive intervals were ordered from smaller to larger, and the values of the $2 \mathrm{nd}, 5 \mathrm{th}, 95 \mathrm{th}$, and 98 th percentiles were determined.

From all these measures (48 in total), we determined those that best represented the different cell types using both plots of the values and a classification program called CTree, an Excel-based classification tree (available at http://butler.redlands.edu/cs/ai/AdotSaha), which uses the $\mathrm{C} 4.5$ algorithm. This program also allowed us to determine the effectiveness of simultaneous use of multiple measures.

Inclusion of data. Units were included in the analysis if the morphology of the cell was unambiguous and, based on the location and depth of the recording, could be unequivocally tied to the recorded activity of the unit. A small number of cells did not show a stable spontaneous activity pattern during the 1-2 min of recording before attempting juxtacellular labeling. Even if the subsequent juxtacellular labeling was successful, the fact that the spontaneous activity pattern varied substantially and inconsistently precluded using it as an identifying signature. For example, the spontaneous activity of several UB cells changed widely with periods of silence (up to $10 \mathrm{~s}$ ) as well as varying periods of regular activity. Such cells were not amenable to the analysis and were not considered further.

\section{Results}

Thorough sequential examination of the transversally cut sections resulted in recovery of most successful juxtacellular labeling attempts (see below). Attempts were considered successful if pulsed current passage resulted in modulated firing (entrainment) of the previously spontaneous firing cell. Although we preferred to maintain entrainment for at least $3 \mathrm{~min}$, shorter entrainment periods could also yield well labeled cells (e.g., granule cells) (see below). An initial quantitative examination of 58 entrained cells from six rats resulted in $38(65 \%)$ well identified cells, $16(28 \%)$ recovered cells insufficiently labeled to permit 

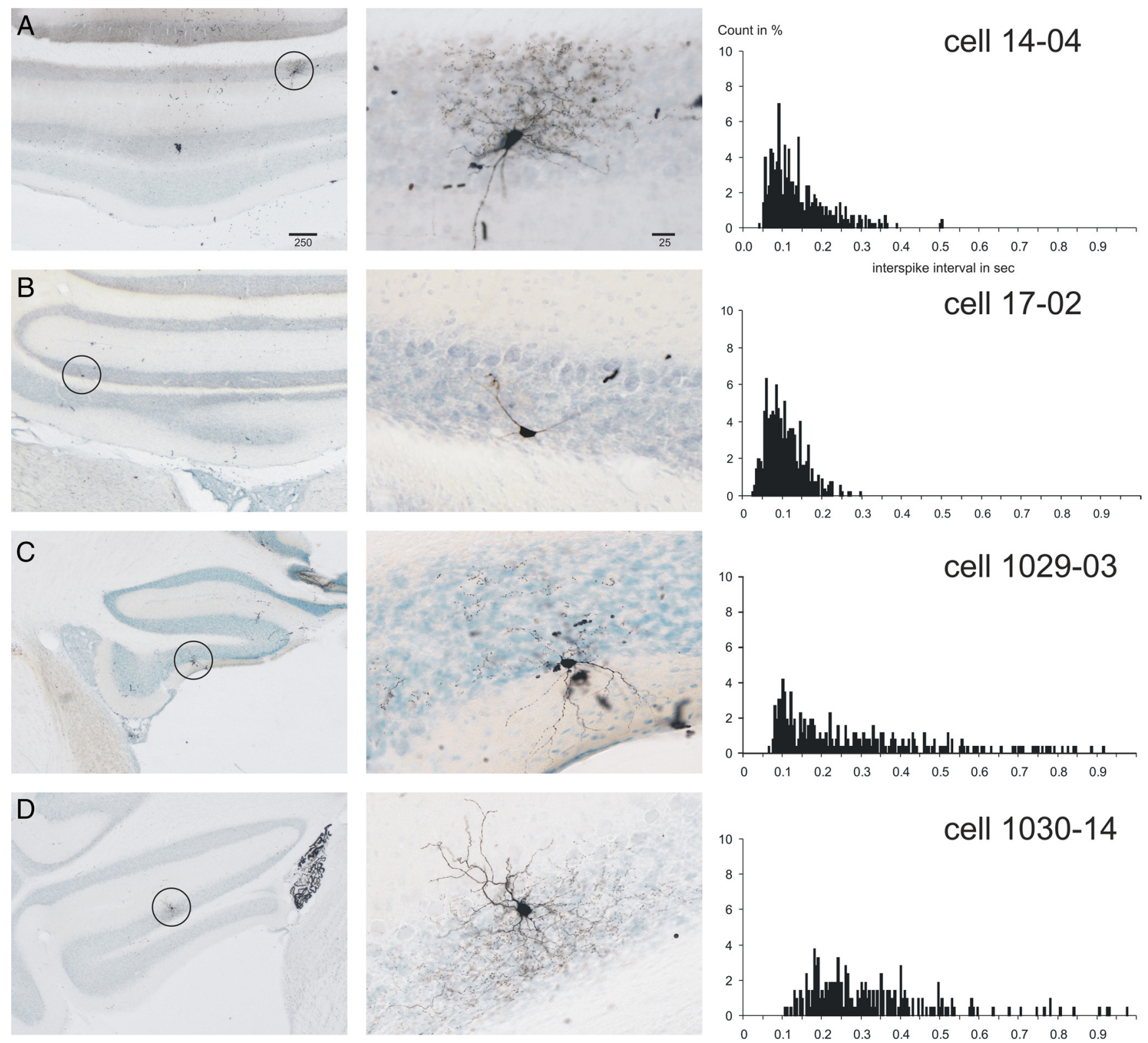

Figure 1. Juxtacellularly labeled rat Golgi cells with the ISI histograms of their respective spontaneous activity. A-D show four representative Golgi cells from the vestibulocerebellum. The left-hand column shows microphotographs of an overview of the location of the labeled cell, which is indicated with a circle. The middle column shows a detail of the labeled cell. The right-hand column shows the ISI histograms based on $60 \mathrm{~s}$ of spontaneous firing (bin width, $5 \mathrm{~ms}$; count in percentage of total counts). Note the dense axonal terminal arborizations of the cells shown in $A$ and $\boldsymbol{D}$. The cell in $\mathbf{C}$ also had similar arborizations best seen in the adjacent section. The cell in $\boldsymbol{B}$ represents large granular layer interneurons that did not show dense terminal arborizations but that also did not fit descriptions of other granular interneuronal types, such as the Lugaro or candelabrum neuron (Lainé and Axelrad, 1994, 1996) or UB cells. The ISI histogram of the cell in $\boldsymbol{B}$ was similar to that of the morphologically typical Golgi cells. Scale bars in $\boldsymbol{A}$ are in micrometers and also apply to $\boldsymbol{B}-\boldsymbol{D}$. The cell shown in $\boldsymbol{A}$ was also shown in the study by Simpson et al. (2005).

classification of the stained structure into one of the six investigated cell types (i.e., Golgi cells, stellate cells, basket cells, UB cells, granule cells, Lugaro cells), and 4 (7\%) unrecovered cells.

Here, we report on the relationship to spontaneous activity of 73 cells identified in the rat caudal cerebellum (primarily ventral uvula and nodulus) and flocculus. In addition, we report similarly on 13 identified cells from the rabbit flocculus. All of the above types of interneurons, except Lugaro cells, whose absence remains a puzzle, were represented in the population of identified cells. We first describe our general observations on the morphology and spontaneous activity of the anatomically identified cells and then illustrate how analysis of the spontaneous activity can be used to identify the types of cerebellar interneurons.

\section{Rat Golgi cells}

Twenty cells were identified as Golgi cells based on morphological criteria. These cells had large somata $(14-22 \mu \mathrm{m})$ located within the granular layer, and in most cases dendrites that reached the molecular layer could also be identified (Fig. 1). In 14 of these 20 cells, pronounced axonal arborizations that carried hundreds of fine varicose punctae believed to be boutons were identified (Fig. 1 $A, C, D$ ). The six additional cells had a distinct morphology in that they did not display a prominent varicose axonal terminal field (Fig. $1 B$ ). These cells were generally localized in the deeper parts of the granular layer. In their spontaneous activity, however, these morphologically "atypical" Golgi cells were not distinct from the morphologically typical Golgi cells (see 

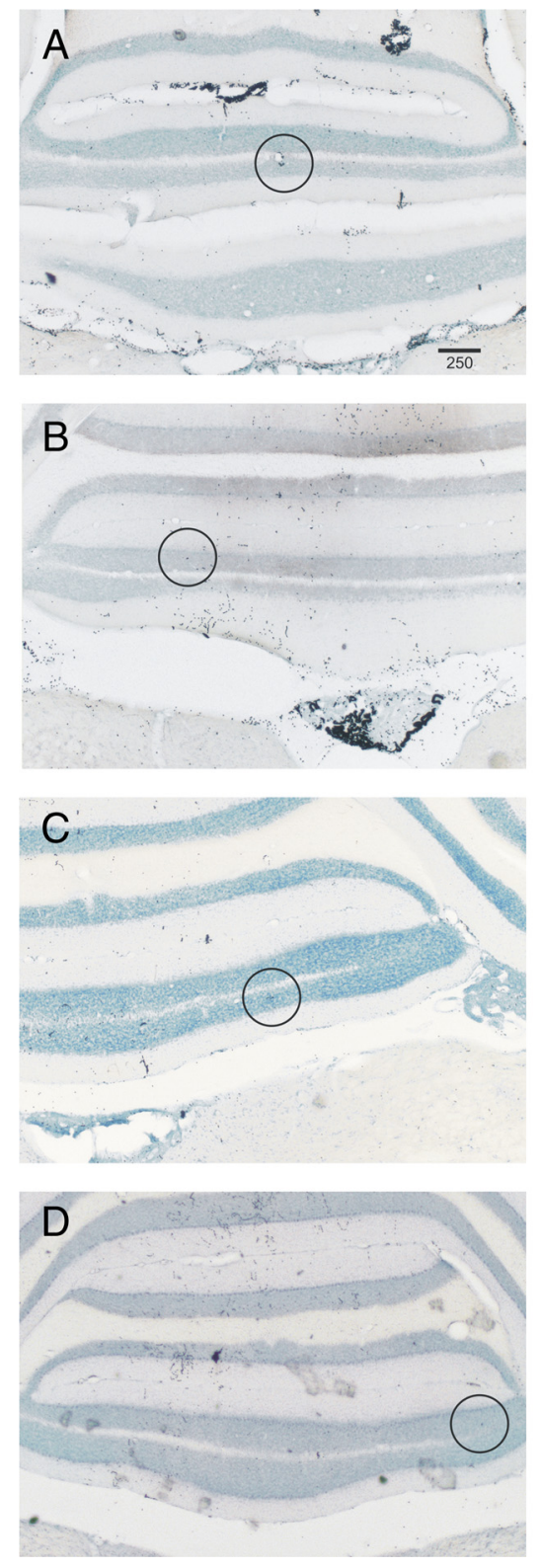
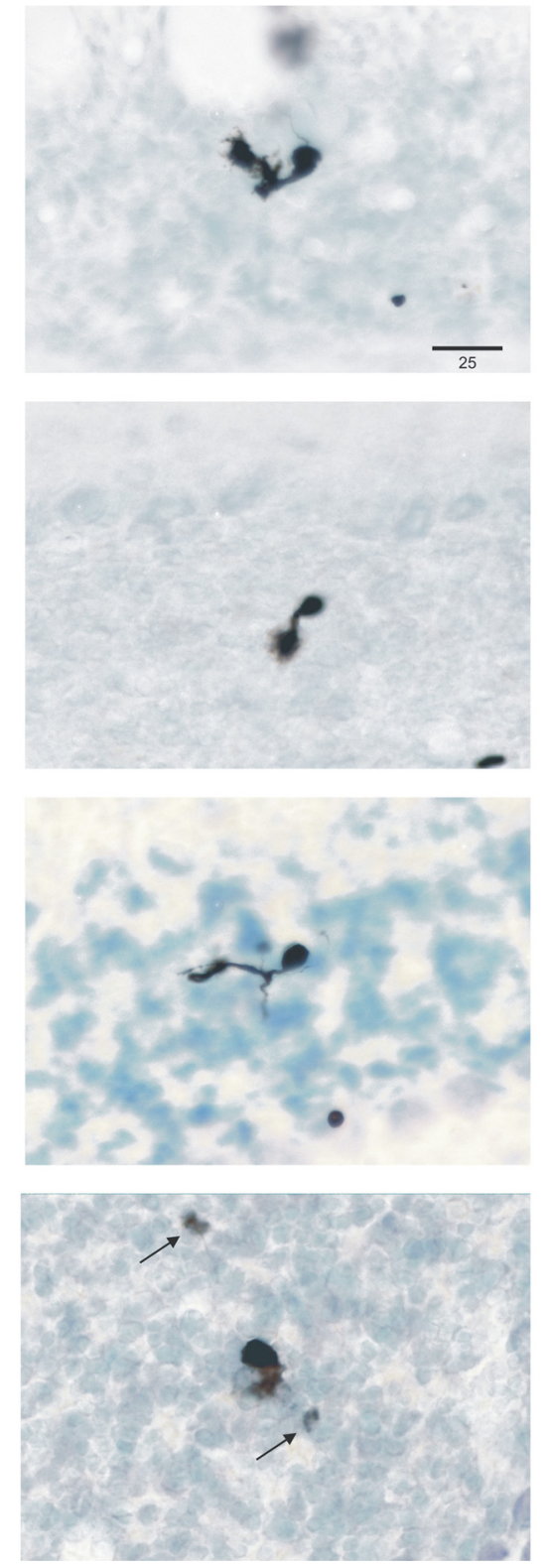
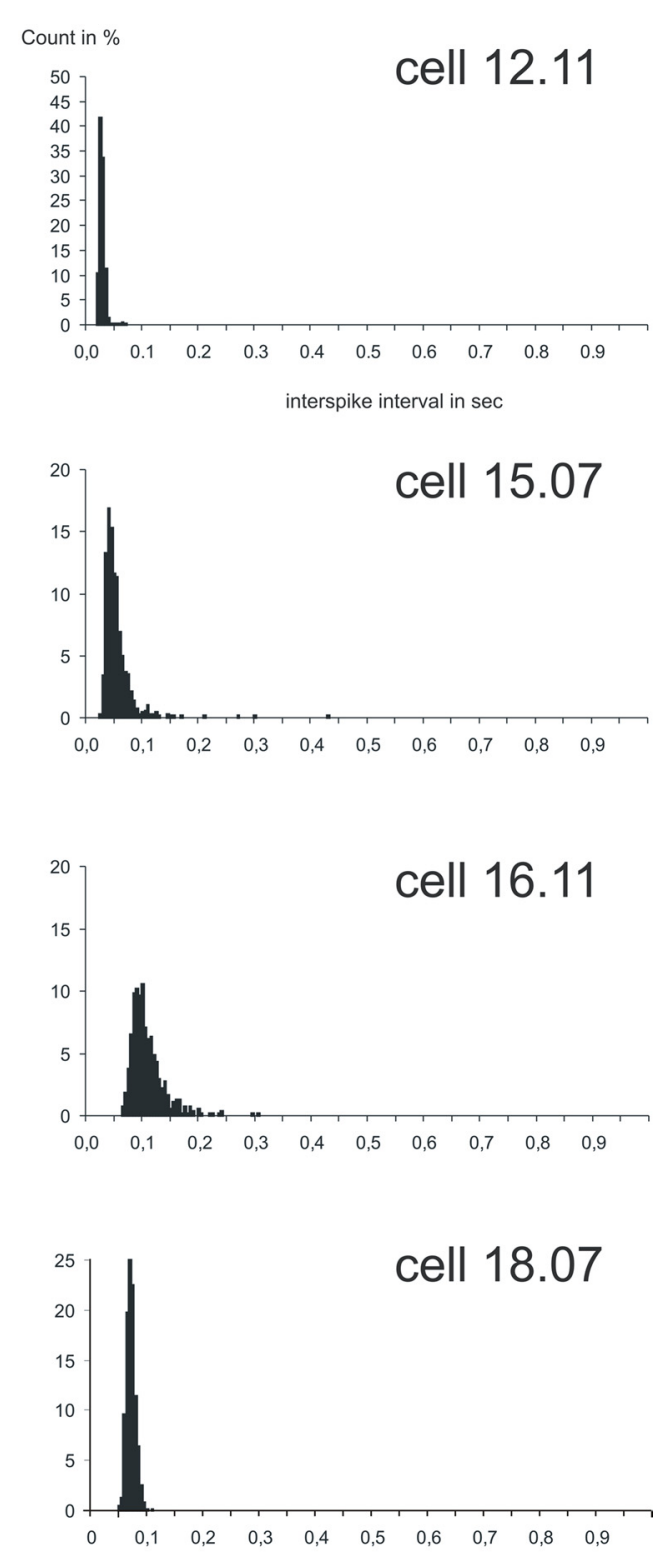

Figure 2. Juxtacellularly labeled rat UB cells with the ISI histograms of their respective spontaneous activity. $A-D$ show four representative UB cells from the vestibulocerebellum. The format is like that of Figure 1. Note that, in general, the shape of the ISI distribution is very narrow $(\boldsymbol{A}, \boldsymbol{D})$ but that it may also have a slight rightward tail ( $\boldsymbol{B}, \boldsymbol{C})$. The arrows in the middle panel of $\boldsymbol{D}$ point to labeled mossy fiber-like rosettes of the axon of the labeled UB cell. Some cells were also shown in the study by Simpson et al. (2005).

below). In addition, the atypical Golgi cell did not resemble, either physiologically or morphologically, the two other known granular layer interneurons, the UB cell and the Lugaro cell. The typical Golgi cells were more often located in the outer half of the granular layer, not infrequently directly adjacent to or even in between the Purkinje cells (Fig. 1C). The average terminal field of three particularly well labeled typical Golgi cells was calculated and found to enclose a volume of $11.0 \pm 0.7 \times 10^{6} \mu \mathrm{m}^{3}$. The anteroposterior and mediolateral widths of the terminal fields were similar for the one nodular Golgi cell (490 and $350 \mu \mathrm{m}$, for unit 14.04) (Fig. 1A) and the two floccular Golgi cells (410 and $540 \mu \mathrm{m}$ for unit $1030.02 ; 380$ and $410 \mu \mathrm{m}$ for unit 1029.01, respectively).

The spontaneous activity of Golgi cells was characterized by generally slow, somewhat irregular firing. The firing frequency of the 20 identified Golgi cells ranged from 1.9 to $11.9 \mathrm{~Hz}$ (mean \pm SEM, $6.1 \pm 0.7$ ). The ISIs varied considerably but were seldomly shorter than $50 \mathrm{~ms}$ (Fig. 1), and the firing usually displayed occasional pauses lasting several hundred milliseconds. The temporal firing characteristics can be observed in plots relating the time of occurrence of an action potential to the $\log _{10}$ of the ISI (in milliseconds) between one spike and the next. Figure $5 A$ shows these plots for the four Figure 1 Golgi cells for $30 \mathrm{~s}$ of consecutive spontaneous firing. Note that for all four cells the distribution of intervals covered a width of approximately an entire order of magnitude (usually between 2 and 3 on the $\log _{10}$ scale, that is, between 100 and $1000 \mathrm{~ms}$ ).

\section{Rat UB cells}

Figure 2 shows the general morphology and ISI histograms of four UB cells. Although the illustrated cells were all localized in lobules IX/X of the caudal cerebellum, UB cells were also encountered in the flocculus. A total of 19 UB cells was identified, and their spontaneous firing behavior was assessed. These cells were 

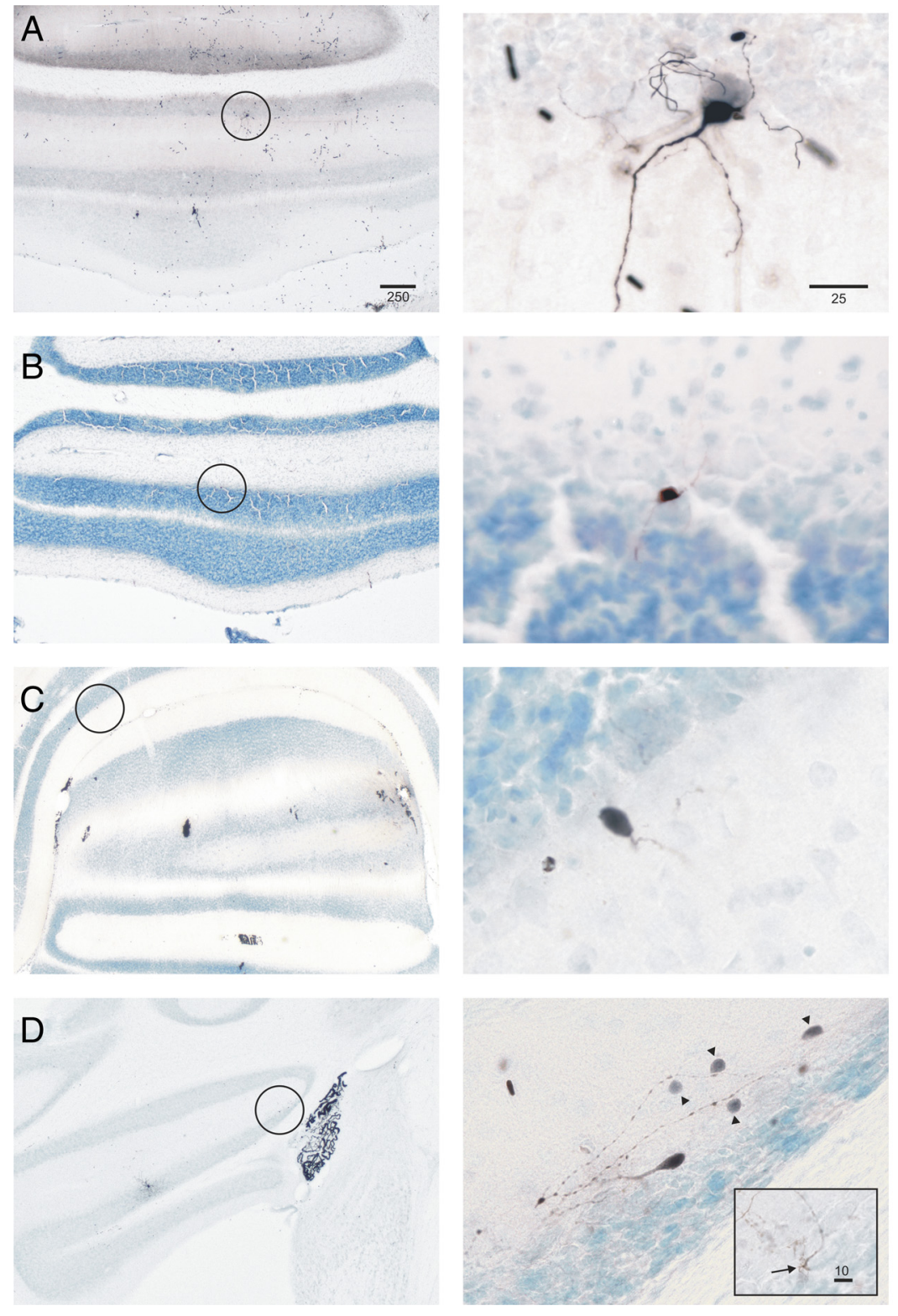
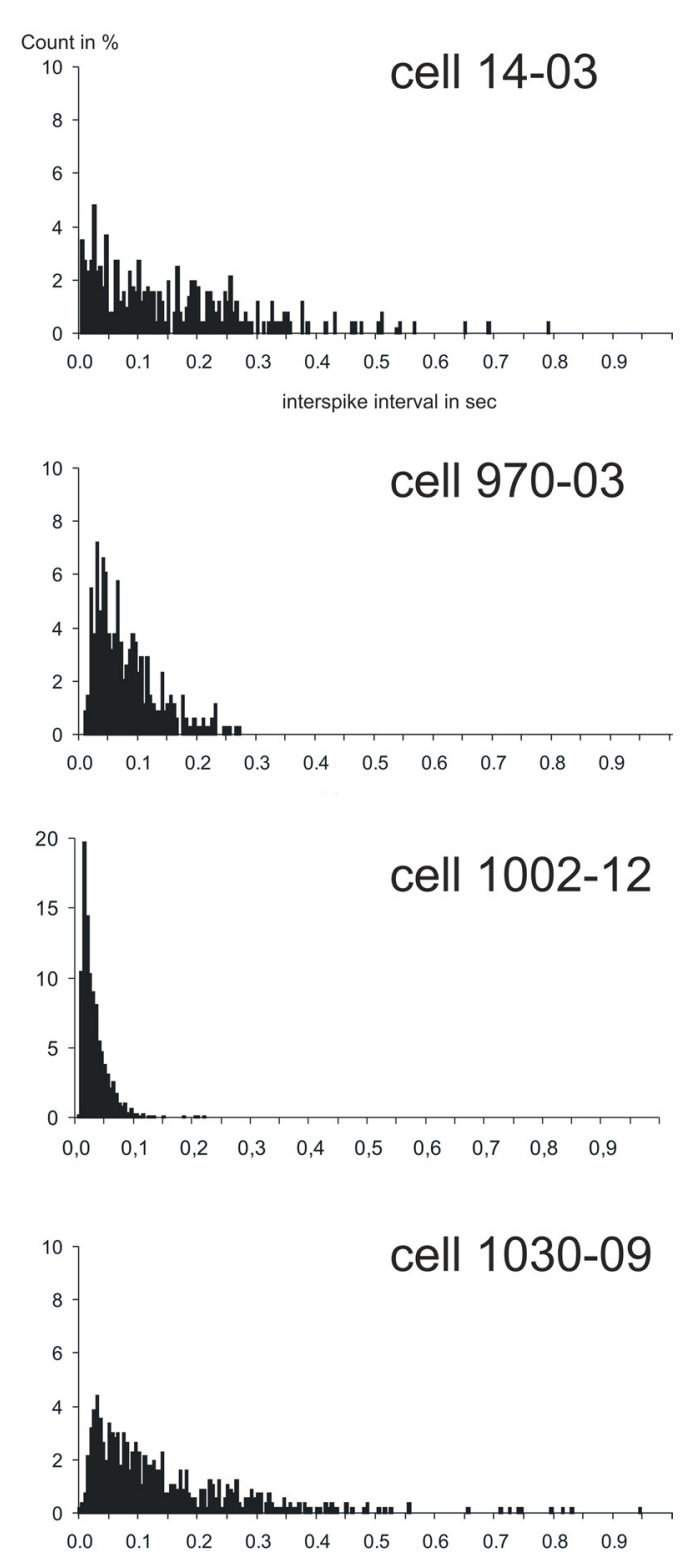

Figure 3. Juxtacellularly labeled rat basket cells with the ISI histograms of their respective spontaneous activity. $\boldsymbol{A}-\boldsymbol{D}$ show four representative basket cells. Conventions are as in Figure 1. Cell 1002.12 (C) was located in ventral lobule VIII but was nevertheless incorporated in our data set as a representative of those basket cells that discharged at the upper end of their firing frequency spectrum. From the ISI distributions, it can be appreciated that typical basket cells displayed a highly irregular firing pattern with many short intervals as well as many longer intervals (except for 1002.12). The arrow in the inset in D points to a typical pinceau formation found as an axon collateral of this cell. The arrowheads point to faintly labeled cells that may have become labeled as the result of electrotonic coupling between molecular layer interneurons (Mann-Metzer and Yarom, 1999).

found throughout the granular layer; they had a small soma $(8-10 \mu \mathrm{m})$ and a single characteristic brush-like dendrite that could protrude from the soma in any direction (Fig. 2). As described previously, the brush often carried fine filaments, called dendrioles (Mugnaini and Floris, 1994). A thin axon was frequently seen arising from the soma to terminate locally in a number of small mossy fiber-like rosettes (Fig. 2D).

The spontaneous firing frequency of UB cells averaged between 7.0 and $47.3 \mathrm{~Hz}$ (mean, 17.6 \pm 2.7 ), which is notably higher than the average firing frequency of Golgi cells. More characteristic, however, was their general regularity in firing, shown by the sharpness of the ISI distributions of the UB cells in Figure 2. The successive $\log _{10}$ ISI plots for these four UB cells are shown in Figure $5 B$. Note that the regularity of firing is indicated by the rather narrow distribution of intervals (usually well within one- half an order of magnitude). These plots also show that some ISIs occasionally show a distinct second band in the $\log _{10}$ plot of successive intervals, indicating that an action potential was missing from the regular pattern (see Fig. 5B, unit 12.11).

\section{Rat basket cells}

Four characteristic basket cells from our sample of 12 are shown in Figure 3. They were identified by their position close to or within the Purkinje cell layer, their small cell bodies $(10-15 \mu \mathrm{m})$, and their axonal arborizations displaying thickened strands (pinceaux) that descended along the somata of Purkinje cells. These axonal arborizations were prominent mostly in the longitudinal direction within lobules IX/X but were transversally oriented in the flocculus (Fig. 3D). In some instances, a number of faintly labeled molecular layer interneurons could be observed in the 

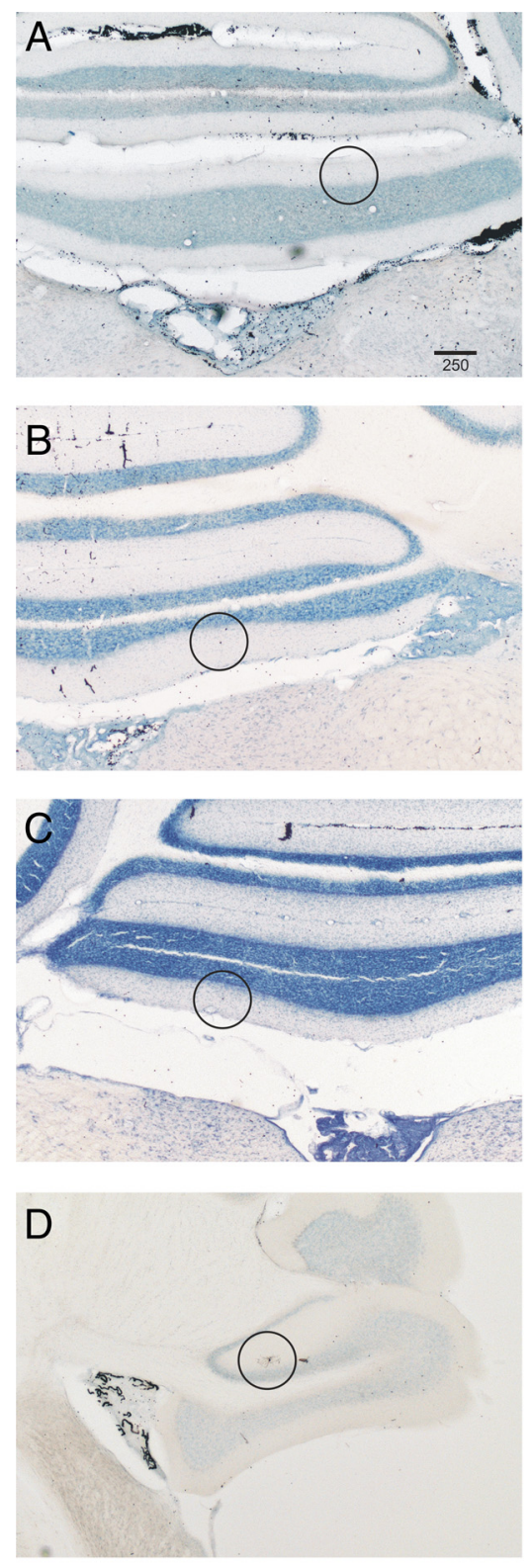
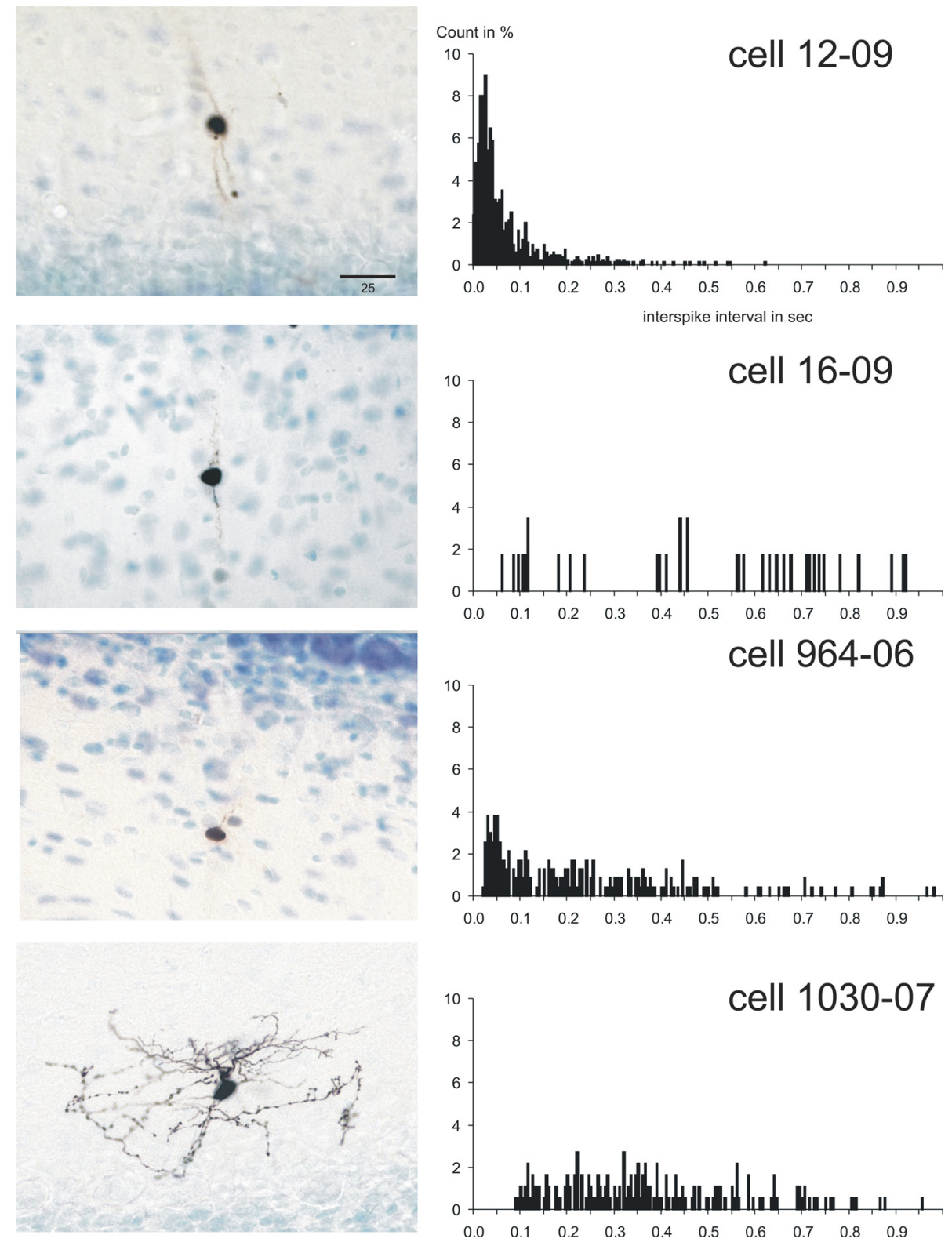

Figure 4. Juxtacellularly labeled rat stellate cells with the ISI histograms of their respective spontaneous activity. $\boldsymbol{A}-\boldsymbol{D}$ show four stellate cells, three in the nodulus $(\boldsymbol{A}-\boldsymbol{C})$ and one in the flocculus (D). Conventions are as in Figure 1. Note that the dendritic orientation of the nodular cells is mostly in the rostrocaudal direction with little spread in the mediolateral direction, whereas the floccular stellate cell shows prominent dendritic arborizations in the mediolateral direction. The ISI distributions reflect a highly irregular pattern of firing.

vicinity of the juxtacellularly labeled neurons. These "ghost" cells most likely become labeled by way of their electrotonic coupling with the recorded and juxtacellularly labeled cell (Mann-Metzer and Yarom, 1999). Ghost cells were usually found along the same direction as the axonal terminations.

The firing behavior of basket cells was very diverse from cell to cell and ranged from slow to fast firing (range, $1.8-35.5 \mathrm{~Hz}$; mean, $10.4 \pm 2.8$ ). However, in contrast to Golgi cell and especially UB cell activity, the firing of basket cells was characteristically irregular. Pauses lasting for up to one-half a second or more were intermingled with occasional ISI values of $10 \mathrm{~ms}$ or less (Figs. $3 A, D, 5$ ). Only when the average firing frequency was high did the longer pauses disappear from the ISI histogram (Fig. $3 B, C)$. However, the regularity of firing did not obtain the level found for the UB cells. This difference is also readily observed from the successive interval plots shown in Figure 5C. Note that the distribution of ISIs extends widely and spans at least one and one-half orders of magnitude or, in case 1002.12 in which the width of the distribution was approximately one order of magnitude, the average firing frequency was much faster than that of the Golgi cells.

\section{Rat stellate cells}

Figure 4 shows four examples of our 16 stellate cells. Like the basket cells, these molecular layer interneurons possessed small cell bodies $(8-12 \mu \mathrm{m})$ and had several dendrites that were distributed mostly perpendicularly to the surface in an anteroposterior direction (Fig. 4A-C). Only the stellate cells that were labeled within the flocculus displayed a dendrite that was oriented mediolaterally (Fig. 4D). When the axon of a stellate cell was clearly labeled, it showed an orientation that was mostly in accordance with the dendritic orientation of the cell (Fig. 4D). Although stellate cells were labeled throughout the molecular layer, most cells within our sample were observed in the middle portion of 

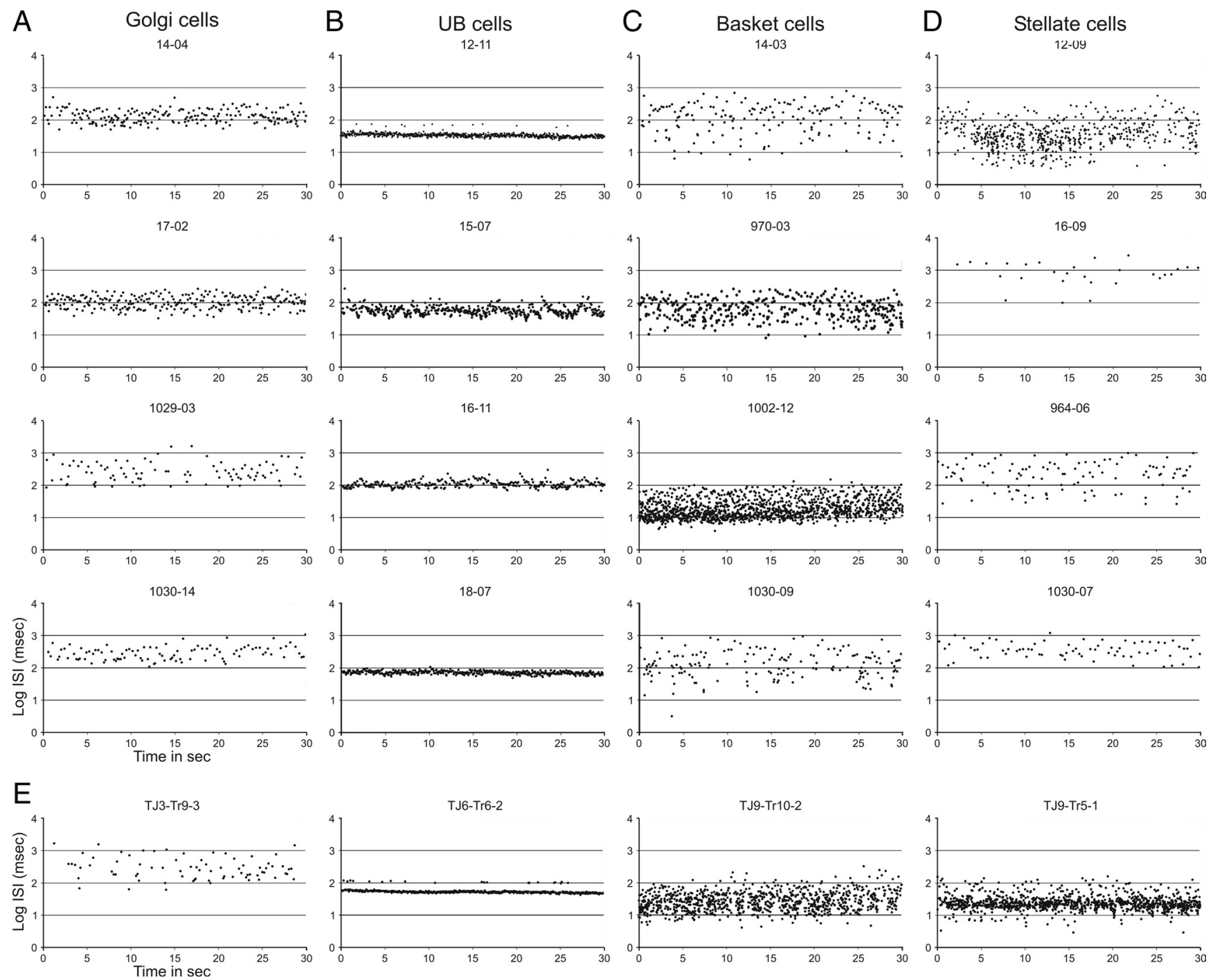

Figure 5. The temporal firing pattern examined by plotting successive ISIs against time. $\boldsymbol{A}-\boldsymbol{D}$ show the successive ISIs for 30 s of spontaneous activity of the Golgi cells shown in Figure 1 ( $A$ ), the UB cells shown in Figure $2(\boldsymbol{B})$, the basket cells shown in Figure $3(\boldsymbol{C})$, and the stellate cells shown in Figure $4(\boldsymbol{D})$. Intervals are indicated as the $\log _{10}$ of the intervals in milliseconds. Note that the distribution of ISIs for the Golgi cells is mostly found between 2 and 3 on the $\log _{10}$ scale $(\boldsymbol{A})$, whereas for the UB cells it is much narrower (less than one-half a $\log _{10}$ unit: $\left.\boldsymbol{B}\right)$. Both basket $(\boldsymbol{C})$ and stellate (D) cells have a wider distribution usually exceeding one $\log _{10}$ unit. Although some cells from different classes may show rather similar temporal distributions (compare bottom panels of $\boldsymbol{A}$ and $\boldsymbol{D}$ ), they can be distinguished using other measures of the spontaneous firing pattern (compare Fig. 8). $\boldsymbol{E}$, Temporal plots of the successive ISIs of the four identified rabbit cells shown in Figure 6 . Note that, in general, the pattern is quite similar to that found for the rat cells of the same class.

this layer. As with the basket cells, stellate cells also could be accompanied by one or several ghost cells (data not shown).

The firing behavior of stellate cells was very similar to that observed for basket cells. Their firing frequency ranged from 0.6 to $30.5 \mathrm{~Hz}$ (mean, $8.3 \pm 1.9$ ). Like basket cells, they could also show a broad distribution of their successive ISIs (Fig. 5D). A few stellate cells (Fig. $4 B, D$ ), and basket cells (data not shown), were conspicuous by their slow spontaneous firing rate. As presented below, this characteristic was used to distinguish a slowly firing subgroup of stellate and basket cells

\section{Rabbit floccular interneurons}

We validated the results obtained in the ketamine/xylazineanesthetized rats by obtaining juxtacellular recordings and labeling in the flocculus of the ketamine/xylazine-anesthetized rabbit. In five rabbits, 13 identified interneurons, including five granule cells, were recovered for correlation with recordings of their spontaneous activity. Examples of a Golgi, UB, basket, and stel- late cell are shown in Figure 6. The Golgi cell (Fig. 6A) was classified as such even though it was located in the molecular layer. The presence of molecular layer, or ectopically placed, Golgi cells is, however, well known for the rabbit (Ramón y Cajal, 1911; Spacek et al., 1973). In addition, its soma size (diameter, 14.8 $\mu \mathrm{m}$ ) falls outside the range for basket and stellate somata (Llano and Gerschenfeld, 1993). Finally, the general morphology of the soma and primary dendrites of these cells is quite similar to that of rat Golgi cells. Indeed, the pattern of spontaneous firing as reflected in both the ISI histogram (Fig. $6 A$ ) and the successive ISI distribution (Fig. 5E) is remarkably similar to that of rat Golgi cells. Identified UB cells in the rabbit, as in the rat, displayed a very regular firing pattern with only an occasional missing action potential (Figs. 5E, 6B). Last, in the rabbit, both basket and stellate cells (Figs. 5E, 6C,D) displayed a fast, but somewhat irregular firing pattern that, in its successive ISI distribution, spanned more than an order of magnitude, thereby resembling rat basket and stellate cells (Fig. 5C,D). 

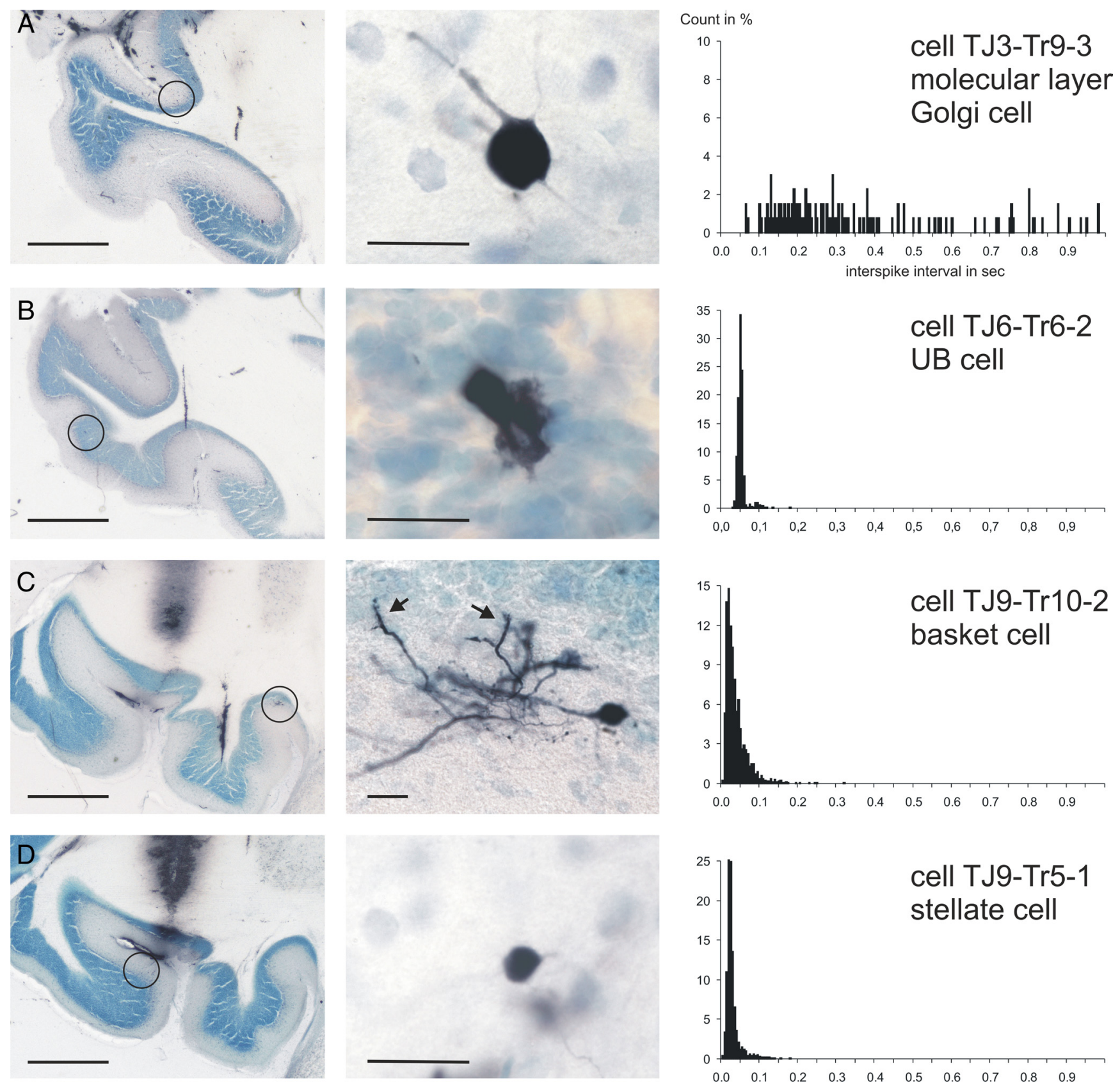

Figure 6. Overview and detail of juxtacellularly labeled interneurons of the rabbit flocculus with the respective ISI histograms of their spontaneous activity. A, A Golgi cell located in the molecular layer (Spacek et al., 1973). Note the irregular firing as shown in the ISI histogram and the absence of the short interval ISIs characteristic of basket and stellate cells. B, A UB cell with an extremely regular firing pattern. The second peak at twice the average $I S I$ duration reflects the occasional absence of spikes from the overall pattern (compare Fig. $5 E$, second panel). $C$, A basket cell with a high firing rate and consequently many short ISIs $(<25 \mathrm{~ms}$ ), but also with several longer intervals $(>200 \mathrm{~ms})$. The arrows (middle panel) point to pinceau formations of the axon. $\boldsymbol{D}, A$ stellate cell with high-frequency firing and thus with many short intervals $(<25 \mathrm{~ms})$. Overall, the morphological and firing characteristics of these interneuron classes are similar to those observed in the rat. Scale bars: (in overviews) $1000 \mu \mathrm{m}$; (in the details) $25 \mu \mathrm{m}$.

\section{Granule cells}

When the microelectrode was in the rabbit granular layer, we often recorded briefly from cells that discharged short, intermittent bursts with very high intraburst frequencies that could exceed $400 \mathrm{~Hz}$. On the two occasions when we were able to juxtacellularly label these cells, they turned out to be granule cells (Fig. $7 A, B$ ). Since this distinctive sporadic high-frequency bursting pattern was commonly seen in the rabbit granule cell layer, we concluded that it is one characteristic of the spontaneous activity of granule cells. The other three labeled granule cells in the rabbit were silent (Fig. 7C,D); the six labeled granule cells in the rat did not show spontaneous bursting and four of them were also silent (Fig. $7 E-G$ ). In such instances in which a labeled granule cell was recovered, the juxtacellular current delivery produced a brief entrainment of activity other than that of the originally targeted spontaneously active cell (Fig. 7E). This entrainment was characterized by extremely high instantaneous firing frequencies of $300-400 \mathrm{~Hz}$. Apparently, during these bouts of entrainment, otherwise silent granule cells were entrained and labeled. Although we presently cannot say whether the silent granule cells may have another type of activity pattern with other input conditions (Jörntell and Ekerot, 2006; Barmack and Yakhnitsa, 
A1
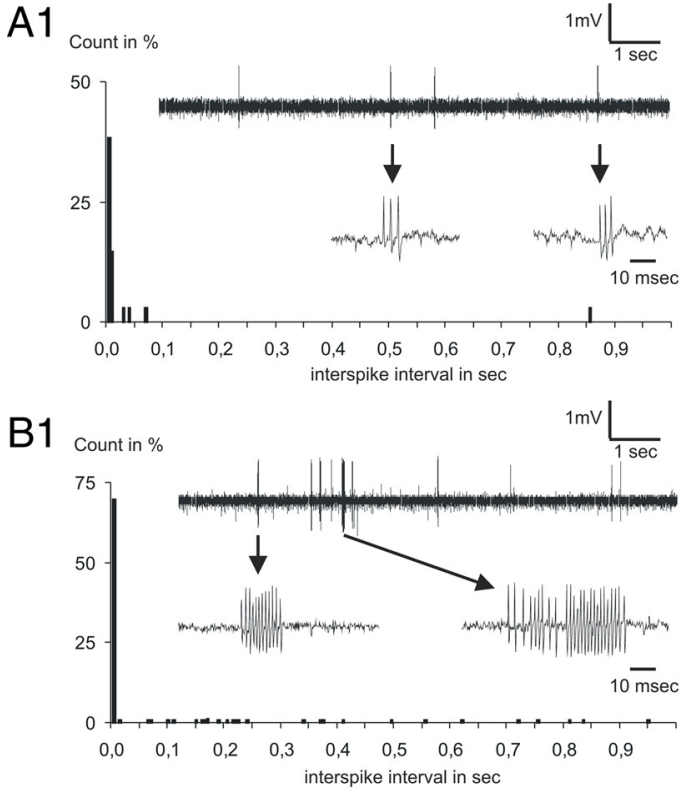

E1

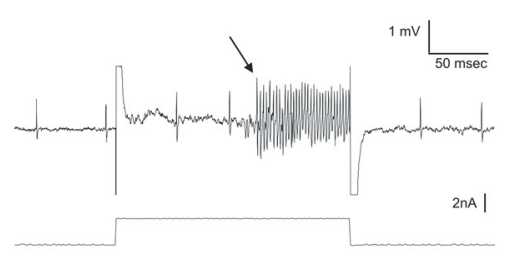

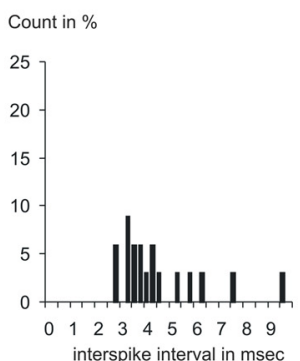
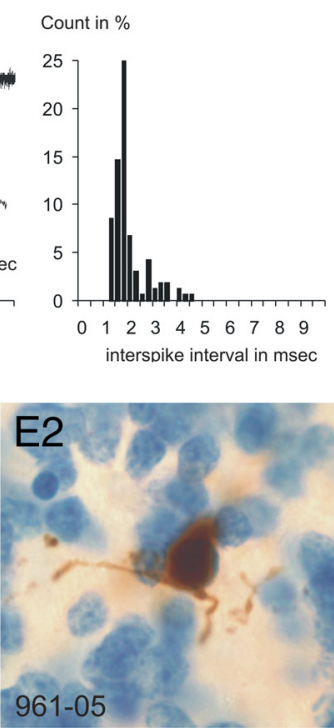
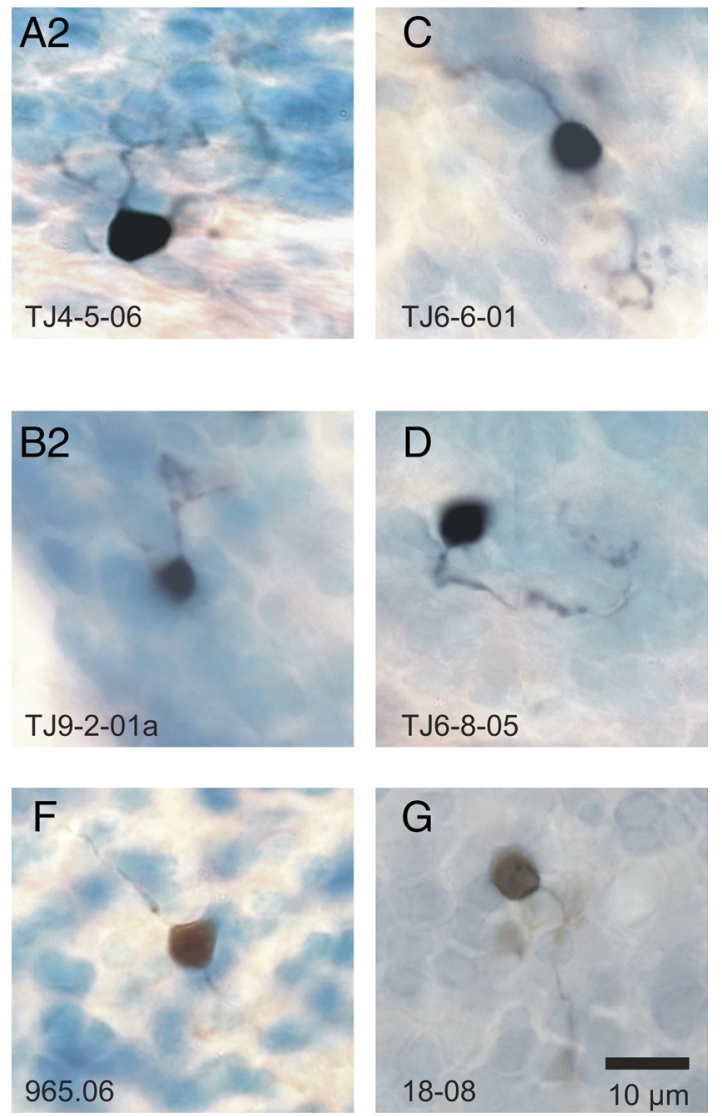

Figure 7. Juxtacellular labeling of granule cells in rat and rabbit. $\boldsymbol{A}$, The spontaneous activity $(\boldsymbol{A} \mathbf{1})$ and resulting morphology $(\boldsymbol{A} \boldsymbol{2})$ of a granule cell from the rabbit flocculus. This cell fired occasional short bursts consisting of a few action potentials at high frequencies (arrows) as indicated by the ISI histogram (A1, right-hand panel). $\boldsymbol{B}$, Spontaneous activity (B1) and morphology (B2) of another rabbit floccular granule cell displaying high-frequency bursts that could last up to several tens of milliseconds with instantaneous frequencies exceeding $600 \mathrm{~Hz}$ (B1, right-hand panel). $\boldsymbol{C}, \boldsymbol{D}$, Additional examples of labeled granule cells from the rabbit flocculus. E1, Activity during juxtacellular current delivery that induced entrainment of a rat granule cell. The arrow points to the moment that an otherwise-silent unit started to become entrained by the applied juxtacellular pulse. A simultaneously recorded, but not entrained cell had the regular spontaneous activity pattern characteristic of a UB cell. E2, Microphotograph of the granule cell that was recovered at the location of the entrainment shown in E1. F, G, Two other rat granule cells that were labeled in conjunction with a high-frequency entrainment similar to that of the cell shown in E1.

2008), we note that the combination of high firing frequencies during periods of entrainment and the resulting labeling of granule cells was never seen in the juxtacellular entrainments that did not result in recovered granule cells and, therefore, seem to represent a specific trait of granule cells.

\section{Identification of interneuron types based on spontaneous activity}

For future physiological experiments, it would be advantageous if an algorithm based on the statistics of spontaneous activity could be developed to reliably classify any cell encountered in either the rat or rabbit vestibulocerebellum. In creating such an algorithm, we required robustness and the ability to make clear separations among classes of cells before incorporating a particular statistical measure. After several attempts at constructing an algorithm that worked for all cells in an initial randomly selected population of 34 rat cells, it became clear that "border zones" containing cells that were to be considered unclassifiable were necessary because their firing pattern too closely resembled that of another type of cell. The resulting classification algorithm was then tested on the remaining group of 39 morphologically identified cells in the rat and modest adjustments were made. The algorithm was then applied to the entire data set, including the 13 cells identified in the rabbit to determine its ability to make correct classifications.
The following statistical measures were found to be most useful in representing the differences in spontaneous activity (see Materials and Methods for the complete list and description of the measures considered): (1) the average firing frequency, 2) the median ISI, 3) the CVlog (the coefficient of variation of the distribution of the natural logarithm of ISIs in milliseconds), (4) the CV2 (mean of twice the absolute difference of successive ISIs divided by the sum of the two intervals), and (5) the fifth percentile interval of the ISI distribution. Table 1 presents an overview of the averages and SDs of these five measures determined for our entire sample of cells.

The classification process is shown in Figure 8 and involved four successive decision steps. After each step, the cells whose identity was decided on as well as the border cells were removed from the population and the remaining cells were carried to the next decision step. Note that the order of the steps was essential for a successful outcome of the classification procedure.

The first decision step separates most granule cells from the other cell types. Since a number of morphologically identified granule cells did not, or hardly, displayed spontaneous activity, we used as one criterion a firing frequency $<0.5 \mathrm{~Hz}$. Other granule cells with spontaneous activity were very irregular, with both very short intervals during high-frequency bursts and very long intervals between bursts. Because of this type of firing, such gran- 
Table 1. Averages and SDs by anatomical cell type for the statistical measures used in the decision algorithm

\begin{tabular}{llclll}
\hline & Cvlog & AvgFreq & CV2 & ISIperc05 & ISImed \\
\hline Granule cells $(n=11)^{a}$ & $0.531 \pm 0.484$ & $0.51 \pm 0.83$ & $0.892 \pm 0.370$ & $0.055 \pm 0.071$ & $0.168 \pm 0.188$ \\
UB cells $(n=23)$ & $0.065 \pm 0.036$ & $17.36 \pm 8.72$ & $0.191 \pm 0.111$ & $0.046 \pm 0.019$ & $0.063 \pm 0.025$ \\
Basket cells $(n=14)$ & $0.195 \pm 0.070$ & $13.66 \pm 12.51$ & $0.761 \pm 0.207$ & $0.030 \pm 0.037$ & $0.118 \pm 0.110$ \\
Stellate cells $(n=17)$ & $0.149 \pm 0.055$ & $9.92 \pm 10.11$ & $0.649 \pm 0.231$ & $0.063 \pm 0.077$ & $0.237 \pm 0.333$ \\
Golgi cells $(n=21)$ & $0.114 \pm 0.024$ & $5.93 \pm 3.10$ & $0.540 \pm 0.131$ & $0.075 \pm 0.032$ & $0.169 \pm 0.087$ \\
\hline
\end{tabular}

${ }^{a}$ Granule cells that did not show spontaneous activity $(n=7)$ were included in the AvgFreq but were not included in the other statistics for which $n=4$. Note that both rat and rabbit cells are combined in the table.
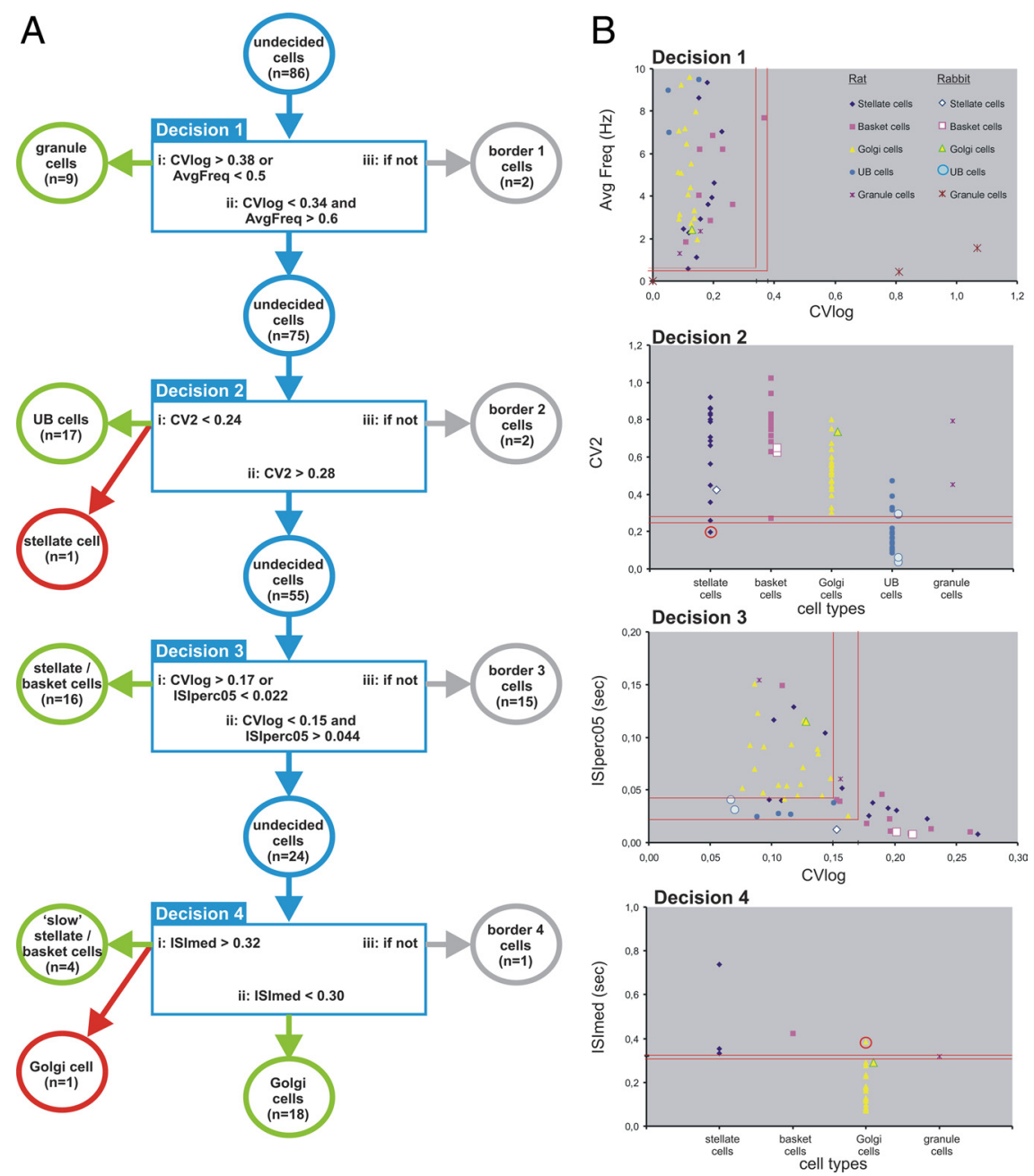

Figure 8. The decision process based on selected statistical measures of spontaneous activity and the relation to morphologically identified interneurons in the rat and rabbit ( $n=86$ cells). $A$, Diagram of the four successive decision steps used to discriminate in sequential order granule cells, UB cells, basket/stellate cells, and, finally, slow basket/stellate cells from Golgi cells. Sixty-four cells were correctly identified by the algorithm (indicated by the green circles). Two cells were wrongly classified (red circles; also in $\boldsymbol{B}$ ). The border categories are included in the decision process to reduce the number of misclassified cells; 20 cells fell into border categories (gray circles). See text for additional explanation. $\boldsymbol{B}$, Diagrams showing graphically the values of the relevant measures used at each step in the decision process. The top diagram (labeled "Decision 1") includes all cells as well as identification of the various symbols in relation to the different cell classes. The rabbit granule cell symbol at $(0,0)$ represents three rabbit and four rat granule cells. In the sequential diagrams (Decisions 2,3 , and 4), the cells on which no decision was made to include them into either a particular class or the border category in the previous decision step are shown. Note that, in the top panel (Decision 1), the cells with average frequencies exceeding $10 \mathrm{~Hz}$ are not plotted. However, all these cells also had a CVlog value $<0.34$ and thus were carried to the next decision step (Decision 2). See text for additional explanation.

ule cells usually had CVlog values $>0.38$, which served as an alternative criterion to the average frequency. In this way, $82 \%$ $(n=9)$ of the 11 granule cells were properly classified. Cells with a CVlog $<0.34$ and with an average firing frequency $>0.6 \mathrm{~Hz}$ $(n=75)$ were moved to the next decision step. The remaining two cells (a basket and a stellate cell) were designated as border cells.

The second decision step takes advantage of the regular firing pattern of UB cells. We found that the regularity of firing is best characterized by the CV2 statistic (Holt et al., 1996). The use of CV2 enabled classification of 17 of the 23 morphologically identified UB cells, leaving 6 UB cells unidentified. These became border cells later in the decision process. Also, at this step, one regularly firing stellate cell was incorrectly classified as a UB cell.

Next, several ways were considered to sort out the molecular layer interneurons from the large granular layer interneurons such as Golgi cells. Careful tracking of the movement of the recording pipette between the molecular and granular layers using the physiological characteristics of complex spike recording (Eccles et al., 1966a) might be helpful in deciding in which of the two layers the cell was located. However, it is not always straightforward to use the polarity of the complex spike to firmly determine the actual layer of the recording site, especially at the border between the molecular and granule cell layers and in the deeper and convoluted lobules of the cerebellar cortex. Moreover, our morphological results revealed that both Golgi cells and basket cells may be very close to or even located among the somata of Purkinje cells. Therefore, we looked for statistical measures to distinguish the molecular layer interneurons from the Golgi cells. We noted that most molecular layer interneurons fire at a higher and usually more irregular rate than Golgi cells. Furthermore, it was not uncommon that basket and stellate cells sometimes displayed two or more successive spikes at short intervals $(<10$ $\mathrm{ms})$. The characteristic irregular firing rate of molecular layer interneurons was captured by the requirement that the CVlog be $>0.17$ or that $5 \%$ of the ISIs are $<22 \mathrm{~ms}$. Using one or the other of these two discrimination criteria, 16 stellate/basket cells were properly classified. However, to reduce incorrect identification of the remaining molecular layer interneurons, a rather wide border area was used, resulting in a fairly large border group of 15 cells. Careful examination of all our measures did not reveal 
any that was of practical significance for dividing the stellate cell from the basket cell class.

The remaining group of 24 cells consisted mostly of Golgi cells $(n=19)$. However, the morphology of cells in this group also revealed four molecular layer interneurons that were conspicuous by their rather slow firing frequency $(1.92 \pm 0.30$ $\mathrm{Hz} ; n=4)$. The Golgi cells within the remaining group of 20 cells discharged at a distinctly higher rate (mean, $5.42 \pm 0.64$ $\mathrm{Hz} ; n=19$ ). The slowly firing molecular layer interneurons and the Golgi cells were best separated by the ISImed, which for 18 of the 19 Golgi cells was $<300 \mathrm{~ms}$, whereas it was $>320 \mathrm{~ms}$ for the group of three stellate cells and a single basket cell, which was termed "slow" stellate/basket cells. One Golgi cell fell incorrectly within the slow category. The remaining granule cell was classified as a border cell in this final decision step. Figure 9 shows the overall classification results of the decision algorithm for the different classes of cells and for the whole population of morphologically identified cells.

In conclusion, we present an algorithm based on statistical measures of spontaneous activity enabling reliable classification of various types of interneurons in the vestibulocerebellum of rat and rabbit. The decision algorithm presented here was able to correctly identify essentially $75 \%$ of the cells by their spontaneous activity patterns (Fig. 9). Only $\sim 2 \%$ were categorized in a class that did not match their morphological identification. The remaining cells $(23 \%)$ were placed in border categories. By accepting that not all cells could be correctly identified by their spontaneous activity, we greatly enhanced the reliability of the decision process.

\section{Discussion}

Previously, some types of cerebellar cortical interneurons in anesthetized or awake animals have been said to be identifiable on the basis of aspects of their activity (Edgley and Lidierth, 1987; van Kan et al., 1993; Vos et al., 1999), but only recently have juxtacellular or intracellular labeling techniques been used to identify morphologically the type of recorded interneuron (Jörntell and Ekerot, 2003; Simpson et al., 2005; Holtzman et al., 2006; Barmack and Yakhnitsa, 2008). These latter studies, however, did not extensively compare the spontaneous activity patterns of the different classes of interneurons, as was the specific intention of the present study.

\section{The classification process}

In ketamine/xylazine-anesthetized rats, vestibulocerebellar interneurons can be distinguished using statistics of their spontaneous activity. Moreover, rabbit floccular interneurons showed very similar spontaneous activity distinctions, thereby demonstrating the general applicability of the classification process, which highlights the regular firing of UB cells, the more irregular firing of Golgi cells in combination with a generally lower firing frequency, and the highly irregular firing of stellate and basket cells. Finally, granule cells were either not, or hardly, spontaneously active or displayed occasional short, high-frequency bursts.

Using these characteristics, we devised an algorithm consisting of four decision steps that enabled correct identification of $\sim 75 \%$ ( 64 of 86 ) of the morphologically identified cells. In addi-
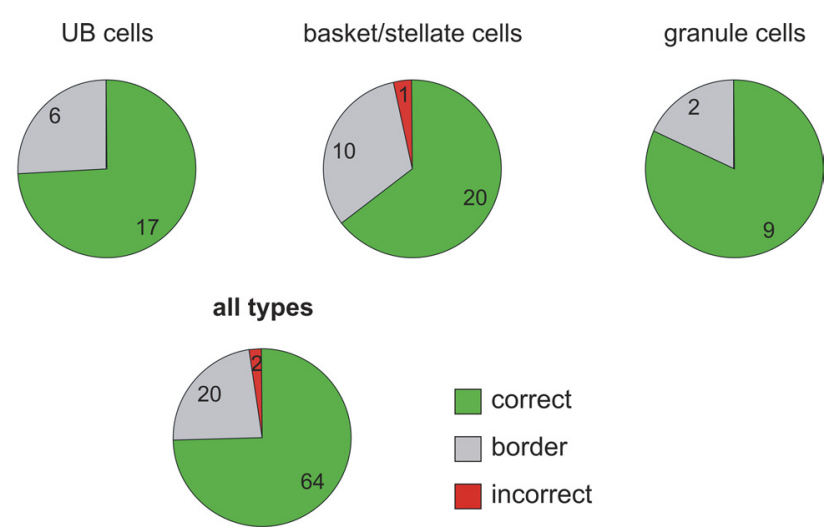

rrect

correct

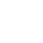

Figure 9. Pie charts showing for each of the anatomically identified types of interneurons, and for the whole population, the sthe cells that was identified correctly, incorrectly, or placed in a border category on the basis of statistical measures characterizing their spontaneous activity. The numbers within each piece of each pie reflect the number of cells within each at and rabbit are combined.

tion, 20 cells were included in border categories, which were used to reduce the chance of incorrect identification. Indeed, in this way, the number of misidentified cells was very low $(n=2)$. We aim to use this decision process to characterize cells recorded during natural vestibular and visual stimulation, not only in the anesthetized, but also in the awake animal (Simpson et al., 2005). Identification with juxtacellular labeling in chronic animals is not regularly feasible because of increased recording instability because of movement and the need to kill the animal within hours after staining. Use of physiological characteristics to identify cerebellar interneurons has become increasingly important in light of the recent surge of studies dealing with their function in cerebellar operations (Jörntell and Ekerot, 2003; D'Angelo, 2008; D'Angelo and De Zeeuw, 2009; Dugué et al., 2009; Wulff et al., 2009).

\section{Golgi cells}

Golgi cells provide both feedforward and feedback inhibition, which is activated directly by mossy fibers and indirectly by parallel fibers, respectively. Golgi cells inhibit granule cells located within their large axonal terminal field and, therefore, are likely to be involved in the selection of signals that reach the molecular layer by the mossy fiber/parallel fiber pathways, thereby regulating the activation of molecular layer interneurons as well as Purkinje cells.

In vivo recordings from putative Golgi cells have shown a large variability in spontaneous firing frequency, with average rates ranging between 2 and $50 \mathrm{~Hz}$ in the awake and locomoting cat (Edgley and Lidierth, 1987), between 10 and $80 \mathrm{~Hz}$ in the flocculus of the awake monkey (Miles et al., 1980), or between 2 and 25 $\mathrm{Hz}$ in the crura of the urethane-anesthetized rat (Holtzman et al., 2006). The upper limits of these rates were never observed in our identified Golgi cells. In the ketamine/xylazine-anesthetized rat, we found average frequencies ranging between 2 and $12 \mathrm{~Hz}$, agreeing with recent data in ketamine/xylazine-anesthetized mice (Barmack and Yakhnitsa, 2008). Moreover, our results show that Golgi cells fire more regularly than molecular layer interneurons, although clearly not as regularly as UB cells. Therefore, the high, very regular frequencies seen in granular layer recordings of the flocculus of the awake monkey (Miles et al., 1980) may not have reflected Golgi cells, but rather UB cells, whose extensive presence in the flocculus was not known at that time. Cells whose ISI histograms are like those of Golgi cells identified in the present study have been found in the vermis of the awake monkey (Prsa et al., 2009). 
Recent observations in slices showed that Golgi cells possess conductances enabling autorhythmicity. In these ex vivo circumstances, Golgi cell firing is extremely regular (Forti et al., 2006), suggesting that synaptic processing in both the anesthetized and awake preparation is responsible for inducing the typical syncopated firing pattern of spontaneously active Golgi cells.

\section{UB cells}

Apart from granule cells, the other small granular layer interneuron is the UB cell. These cells, which are specifically prominent in the vestibulocerebellum (Mugnaini et al., 1997), are now recognized as excitatory neurons that provide local mossy fiber-like terminals (Diño et al., 2000; Nunzi et al., 2001). We found that most UB cells are characterized by a regular firing pattern. Only rarely did some cells exhibit a more irregular pattern. Therefore, in our decision algorithm, the regular firing of UB cells was chosen as the most prominent and reliable distinguishing feature. The basis of the regular tonic firing might be related to the observation that UB cells can be spontaneously active ex vivo (Diana et al., 2007; Russo et al., 2007, 2008). However, discharges of highfrequency bursts, which may be triggered by mossy fiber activation of hyperpolarized UB cells (Diana et al., 2007; Birnstiel et al., 2009), were not seen in the present in vivo study (Simpson et al., 2005; Barmack and Yakhnitsa, 2008).

\section{Molecular layer interneurons}

Basket and stellate cells were originally described as two separate molecular layer cell classes, distinguished by the fact that basket cells supply specific inhibitory axon collaterals to the soma and proximal axon of Purkinje cells (Ramón y Cajal, 1911; Bishop, 1993). Although stellate cells do inhibit Purkinje cells, they do not display axosomatic contacts and are mostly found in the middle and outer parts of the molecular layer. A clear separation of the molecular layer interneurons into two distinct classes has been challenged on morphological and physiological grounds (Sultan and Bower, 1998; Mann-Metzer and Yarom, 1999; Jörntell and Ekerot, 2002). Indeed, our analysis of spontaneous activity did not reveal any systematic difference between identified basket and stellate cells. The rather wide range of average spontaneous firing frequencies $(1-36 \mathrm{~Hz})$ in our rat population of 12 basket and 16 stellate cells in vivo is very similar to that found ex vivo for molecular layer interneurons (Häusser and Clark, 1997; MannMetzer and Yarom, 1999) and also for the ketamine/xylazineanesthetized mouse (Barmack and Yakhnitsa, 2008). Apart from the wide range in the average spontaneous firing rate, the population of our rat molecular layer cells is characterized by rather irregular firing $(\mathrm{CV}, 0.89 \pm 0.10 ; n=28)$. This characteristic was also noted in the ex vivo preparation $(\mathrm{CV}, 0.51 \pm 0.024 ; n=43)$ in which it was shown to be mediated by inhibitory input (Häusser and Clark, 1997).

\section{Granule cells}

Several groups have reported on granule cell physiology in in vivo preparations (Eccles et al., 1966b; Chadderton et al., 2004; Jörntell and Ekerot, 2006; Rancz et al., 2007; Bengtsson and Jörntell, 2009). These studies noted the burst-firing capability of granule cells with instantaneous firing frequencies exceeding $200 \mathrm{~Hz}$, which was related to the firing properties of the afferent mossy fibers. However, in the vestibulocerebellum, most afferents arise from the vestibular system, whose neurons, with the head stationary, fire tonically at frequencies that seldom exceed $100 \mathrm{~Hz}$ (Stahl and Simpson, 1995; Zhang et al., 1995; Cheron et al., 1996; Barmack and Yakhnitsa, 2008). Nevertheless, granule cells in the rabbit can burst with intraburst spike frequencies exceeding 400 Hz. Curiously, in the anesthetized rats, we did not encounter spontaneously bursting granule cells. Although it cannot be excluded that the ketamine/xylaxine anesthesia may have reduced spontaneous granule cell activity (Hevers et al., 2008), activity patterns in the granular layer have been reported to be similar in awake and ketamine/xylazine-anesthetized rats (Hartmann and Bower, 2001; Santamaria et al., 2007). Although the functional behavior of granule cells in the vestibulocerebellum may differ from that proposed for paravermal and hemispheral granule cells (Jörntell and Ekerot, 2006; Rancz et al., 2007; Bengtsson and Jörntell, 2009; Ros et al., 2009), we suggest that the bursting activity of granule cells may be typical for the role they perform in cerebellar functioning.

\section{Conclusions}

We have shown that the spontaneous activity patterns of cortical interneurons in the vestibulocerebellum of the anesthetized rat and rabbit can be used to reliably identify them as a member of one of four classes. Regularly discharging cells can be classified as UB cells, whereas highly irregularly firing cells are most likely molecular layer interneurons. Golgi cells are characterized by a somewhat irregular, syncopated discharge pattern. Finally, vestibulocerebellar granule cells usually display sparse or no spontaneous activity, but can sometimes spontaneously exhibit bursts with extremely high intraburst rates.

An upcoming challenge is to demonstrate the applicability of the present findings in paradigms using awake animals. The similarity between firing characteristics of morphologically identified cells found in ketamine-anesthetized animals and those of spontaneously firing cells in the awake rabbit has been noted previously (Simpson et al., 2005), suggesting that our classification algorithm may be applied successfully to floccular interneurons in awake rabbits (Hensbroek et al., 2006; van Beugen et al., 2006). Indeed, we propose that the algorithm presented may be generally useful in studying the functional behavior of cerebellar interneurons.

\section{References}

Barmack NH, Yakhnitsa V (2008) Functions of interneurons in mouse cerebellum. J Neurosci 28:1140-1152.

Bengtsson F, Jörntell H (2009) Sensory transmission in cerebellar granule cells relies on similarly coded mossy fiber inputs. Proc Natl Acad Sci U S A 106:2389-2394.

Birnstiel S, Slater NT, McCrimmon DR, Mugnaini E, Hartell NA (2009) Voltage-dependent calcium signaling in rat cerebellar unipolar brush cells. Neuroscience 162:702-712.

Bishop GA (1993) An analysis of HRP-filled basket cell axons in the cat's cerebellum. 1. Morphometry and configuration. Anat Embryol 188:287-297.

Chadderton P, Margrie TW, Häusser M (2004) Integration of quanta in cerebellar granule cells during sensory processing. Nature 428:856-860.

Cheron G, Escudero M, Godaux E (1996) Discharge properties of brain stem neurons projecting to the flocculus in the alert cat. I. Medial vestibular nucleus. J Neurophysiol 76:1759-1774.

D'Angelo E (2008) The critical role of Golgi cells in regulating spatiotemporal integration and plasticity at the cerebellum input stage. Front Neurosci 2:35-46.

D'Angelo E, De Zeeuw CI (2009) Timing and plasticity in the cerebellum: focus on the granular layer. Trends Neurosci 32:30-40.

De Zeeuw CI, Wylie DR, Stahl JS, Simpson JI (1995) Phase relations of Purkinje cells in the rabbit flocculus during compensatory eye movements. J Neurophysiol 74:2051-2064.

Diana MA, Otsu Y, Maton G, Collin T, Chat M, Dieudonné S (2007) T-type and $\mathrm{L}$-type $\mathrm{Ca}^{2+}$ conductances define and encode the bimodal firing pattern of vestibulocerebellar unipolar brush cells. J Neurosci 27:3823-3838. 
Diño MR, Schuerger RJ, Liu Y, Slater NT, Mugnaini E (2000) Unipolar brush cell: a potential feedforward excitatory interneuron of the cerebellum. Neuroscience 98:625-636.

Dugué GP, Brunel N, Hakim V, Schwartz E, Chat M, Lévesque M, Courtemanche R, Léna C, Dieudonné S (2009) Electrical coupling mediates tunable low-frequency oscillations and resonance in the cerebellar Golgi cell network. Neuron 61:126-139.

Eccles JC, Llinás R, Sasaki K (1966a) The excitatory synaptic action of climbing fibers on the Purkinje cells of the cerebellum. J Physiol 182:268-296.

Eccles JC, Llinás R, Sasaki K (1966b) The mossy fibre-granule cell relay of the cerebellum and its inhibitory control by Golgi cells. Exp Brain Res 1:82-101.

Edgley SA, Lidierth M (1987) The discharges of cerebellar Golgi cells during locomotion in the cat. J Physiol 392:315-332.

Forti L, Cesana E, Mapelli J, D'Angelo E (2006) Ionic mechanisms of autorhythmic firing in rat cerebellar Golgi cells. J Physiol 574:711-729.

Granit R, Phillips CG (1956) Excitatory and inhibitory processes acting upon individual Purkinje cells of the cerebellum in cats. J Physiol 133:520-547.

Hartmann MJ, Bower JM (2001) Tactile responses in the granule cell layer of cerebellar folium crus IIa of freely behaving rats. J Neurosci 21:3549-3563.

Häusser M, Clark BA (1997) Tonic synaptic inhibition modulates neuronal output pattern and spatiotemporal synaptic integration. Neuron 19:665-678.

Hensbroek RA, van Beugen BJ, Ruigrok TJH, Simpson JI (2006) Spike modulation of unipolar brush cells and granule cells in the awake rabbit. Soc Neurosci Abstr 32:740.2.

Hensbroek RA, van Beugen BJ, Maruta J, Ruigrok TJH, Simpson JI (2007) Spike modulation of basket and stellate cells in the cerebellar flocculus. Soc Neurosci Abstr 33:512.8.

Hevers W, Hadley SH, Lüddens H, Amin J (2008) Ketamine, but not phencyclidine, selectively modulates cerebellar $\mathrm{GABA}_{\mathrm{A}}$ receptors containing $\alpha 6$ and $\delta$ subunits. J Neurosci 28:5383-5393.

Holt GR, Softky WR, Koch C, Douglas RJ (1996) Comparison of discharge variability in vitro and in vivo in cat visual cortex neurons. J Neurophysiol 75:1806-1814.

Holtzman T, Rajapaksa T, Mostofi A, Edgley SA (2006) Different responses of rat cerebellar Purkinje cells and Golgi cells evoked by widespread convergent sensory inputs. J Physiol 574:491-507.

Jörntell H, Ekerot CF (2002) Reciprocal bidirectional plasticity of parallel fiber receptive fields in cerebellar Purkinje cells and their afferent interneurons. Neuron 34:797-806.

Jörntell H, Ekerot CF (2003) Receptive field plasticity profoundly alters the cutaneous parallel fiber synaptic input to cerebellar interneurons in vivo. J Neurosci 23:9620-9631.

Jörntell H, Ekerot CF (2006) Properties of somatosensory synaptic integration in cerebellar granule cells in vivo. J Neurosci 26:11786-11797.

Lainé J, Axelrad H (1994) The candelabrum cell: a new interneuron in the cerebellar cortex. J Comp Neurol 339:159-173.

Lainé J, Axelrad H (1996) Morphology of the Golgi-impregnated Lugaro cell in the rat cerebellar cortex: a reappraisal with a description of its axon. J Comp Neurol 375:618-640.

Llano I, Gerschenfeld HM (1993) Inhibitory synaptic currents in stellate cells of rat cerebellar slices. J Physiol 468:177-200.

Mann-Metzer P, Yarom Y (1999) Electrotonic coupling interacts with intrinsic properties to generate synchronized activity in cerebellar networks of inhibitory interneurons. J Neurosci 19:3298-3306.

Miles FA, Fuller JH, Braitman DJ, Dow BM (1980) Long-term adaptive changes in primate vestibuloocular reflex. III. Electrophysiological observations in flocculus of normal monkeys. J Neurophysiol 43:1437-1476.

Mugnaini E, Floris A (1994) The unipolar brush cell: a neglected neuron of the mammalian cerebellar cortex. J Comp Neurol 339:174-180.

Mugnaini E, Diño MR, Jaarsma D (1997) The unipolar brush cells of the mammalian cerebellum and cochlear nucleus: cytology and microcircuitry. Prog Brain Res 114:131-150.

Nunzi MG, Birnstiel S, Bhattacharyya BJ, Slater NT, Mugnaini E (2001) Unipolar brush cells form a glutamatergic projection system within the mouse cerebellar cortex. J Comp Neurol 434:329-341.

Pijpers A, Voogd J, Ruigrok TJ (2005) Topography of olivo-cortico-nuclear modules in the intermediate cerebellum of the rat. J Comp Neurol 492:193-213.

Pinault D (1996) A novel single-cell staining procedure performed in vivo under electrophysiological control: morpho-functional features of juxtacellularly labeled thalamic cells and other central neurons with biocytin or Neurobiotin. J Neurosci Methods 65:113-136.

Prsa M, Dash S, Catz N, Dicke PW, Thier P (2009) Characteristics of responses of Golgi cells and mossy fibers to eye saccades and saccadic adaptation recorded from the posterior vermis of the cerebellum. J Neurosci 29:250-262.

Ramón y Cajal S (1911) Histologie du système nerveux de l'homme et des vertébrés. Paris: Maloine.

Rancz EA, Ishikawa T, Duguid I, Chadderton P, Mahon S, Häusser M (2007) High-fidelity transmission of sensory information by single cerebellar mossy fibre boutons. Nature 450:1245-1248.

Ros H, Sachdev RN, Yu Y, Sestan N, McCormick DA (2009) Neocortical networks entrain neuronal circuits in cerebellar cortex. J Neurosci 29:10309-10320.

Ruigrok TJ, Apps R (2007) A light microscope-based double retrograde tracer strategy to chart central neuronal connections. Nat Protoc 2:1869-1878.

Ruigrok TJ, Osse RJ, Voogd J (1992) Organization of inferior olivary projections to the flocculus and ventral paraflocculus of the rat cerebellum. J Comp Neurol 316:129-150.

Ruigrok TJ, Teune TM, van der Burg J, Sabel-Goedknegt H (1995) A retrograde double labeling technique for light microscopy. A combination of axonal transport of cholera toxin B-subunit and a gold-lectin conjugate. J Neurosci Methods 61:127-138.

Russo MJ, Mugnaini E, Martina M (2007) Intrinsic properties and mechanisms of spontaneous firing in mouse cerebellar unipolar brush cells. J Physiol 581:709-724.

Russo MJ, Yau HJ, Nunzi MG, Mugnaini E, Martina M (2008) Dynamic metabotropic control of intrinsic firing in cerebellar unipolar brush cells. J Neurophysiol 100:3351-3360.

Santamaria F, Tripp PG, Bower JM (2007) Feedforward inhibition controls the spread of granule cell-induced Purkinje cell activity in the cerebellar cortex. J Neurophysiol 97:248-263.

Simpson JI, Hulscher HC, Sabel-Goedknegt E, Ruigrok TJ (2005) Between in and out: linking morphology and physiology of cerebellar cortical interneurons. Prog Brain Res 148:329-340.

Spacek J, Parízek J, Lieberman AR (1973) Golgi cells, granule cells and synaptic glomeruli in the molecular layer of the rabbit cerebellar cortex. J Neurocytol 2:407-428.

Stahl JS, Simpson JI (1995) Dynamics of rabbit vestibular nucleus neurons and the influence of the flocculus. J Neurophysiol 73:1396-1413.

Sultan F, Bower JM (1998) Quantitative Golgi study of the rat cerebellar molecular layer interneurons using principal component analysis. J Comp Neurol 393:353-373.

van Beugen BJ, Hensbroek RA, Ruigrok TJ, Simpson JI (2006) Spike modulation of Golgi cells in the cerebellum of the awake rabbit. Soc Neurosci Abstr 32:740.3.

van Kan PL, Gibson AR, Houk JC (1993) Movement-related inputs to intermediate cerebellum of the monkey. J Neurophysiol 69:74-94.

Voogd J, Pardoe J, Ruigrok TJ, Apps R (2003) The distribution of climbing and mossy fiber collateral branches from the copula pyramidis and the paramedian lobule: congruence of climbing fiber cortical zones and the pattern of zebrin banding within the rat cerebellum. J Neurosci 23:4645-4656.

Vos BP, Volny-Luraghi A, De Schutter E (1999) Cerebellar Golgi cells in the rat: receptive fields and timing of responses to facial stimulation. Eur J Neurosci 11:2621-2634.

Wulff $\mathrm{P}$, Schonewille M, Renzi M, Viltono L, Sassoè-Pognetto M, Badura A, Gao Z, Hoebeek FE, van Dorp S, Wisden W, Farrant M, De Zeeuw CI (2009) Synaptic inhibition of Purkinje cells mediates consolidation of vestibulo-cerebellar motor learning. Nat Neurosci 12:1042-1049.

Zhang Y, Partsalis AM, Highstein SM (1995) Properties of superior vestibular nucleus flocculus target neurons in the squirrel monkey. I. General properties in comparison with flocculus projecting neurons. J Neurophysiol 73:2261-2278. 